\title{
Surgical Protocol Violations in Children with Renal Tumors Provides an Opportunity to Improve Pediatric Cancer Care: A Report from the Children's Oncology Group
}

Peter F. Ehrlich MD, MSc ${ }^{1}$; Thomas E. Hamilton, M.D. ${ }^{2}$; Kenneth Gow, M.D. ${ }^{3}$; Douglas Barnhart, M.D. ${ }^{4}$; Fernando Ferrer, M.D. ${ }^{5}$, Jessica Kandel, M.D. ${ }^{6}$, Richard Glick, M.D. ${ }^{7}$, Roshni Dasgupta, M.D. ${ }^{8}$; Arlene Naranjo, $\mathrm{PhD}^{9}$, Ying He, M.A.S. ${ }^{13}$;Elizabeth J. Perlman $\mathrm{MD}^{10}$; John A. Kalapurakal MD ${ }^{10}$; ; Geetika Khanna, MBBS ${ }^{11}$ Jeffrey S. Dome MD, $\mathrm{PhD}^{12}$; James Geller, M.D. ${ }^{8}$, Elizabeth Mullen, M.D ${ }^{2}$.

1. C.S. Mott Children's Hospital, University of Michigan, MI, USA.

2. Dana Farber Cancer Institute, Boston Children's Hospital, Boston, MA, USA

3. Seattle Children's Hospital, Seattle, WA, USA

4. Primary Children's Medical Center, Salt Lake, UT, USA

5. Connecticut Children's Hospital, Hartford, CT, USA

6. Comer Children's Hospital University of Chicago, Chicago IL, USA

7. Steven and Alexandra Cohen Medical Center of New York, New York, NY, USA

8. Cincinnati Children's Hospital, Cincinnati, OH, USA

9. Children's Oncology Group (COG) Statistics and Data Center (SDC), University of Florida, Gainesville, FL, USA

10. Luire Children's Hospital Feinberg School of Medicine, Northwestern University, Chicago, IL, USA

11. Washington University School of Medicine, St Louis, MO, USA

12. Children's National Medical Center, Washington, DC.

13. Clarkson University, Potsdam NY, USA

Corresponding Author

P F Ehrlich MD, MSc., Associate Professor of Surgery, University of Michigan Medical

School

fax 734-232-8667

phone 734-763-2072

email pehrlich@med.umich.edu

Text word count $=2693$

Abstract word count $=256$

Brief Running Title Surgical Protocol Violations and Quality

Keywords= Wilms Tumor, Surgery, Quality Improvement

Tables $=1$

Figures $=2$

\begin{tabular}{|l|l|}
\hline Abbreviations \\
\hline Surgical protocol violations & SPV \\
\hline Childrens Oncology Group & COG \\
\hline $\begin{array}{l}\text { American College of Surgeons Pediatric National Surgical Quality } \\
\text { Improvement Program-Pediatric }\end{array}$ & NSQIP- \\
\hline Peds \\
\hline Socienal Wilms Tumor Study Group & NWTSG \\
\hline
\end{tabular}

This is the author manuscript accepted for publication and has undergone full peer review but has not been through the copyediting, typesetting, pagination and proofreading process, which may lead to differences between this version and the Version of Record. Please cite this article as doi: $10.1002 / \mathrm{pbc} .26083$.

This article is protected by copyright. All rights reserved. 


\section{Acknowledgements}

This project was supported by grants CA98543 (Children's Oncology Group Chair's grant) and CA98413 (COG SDC grant) from the National Institutes of Health. U10CA180899

\section{The authors have NO conflicts of interest}

Abstract

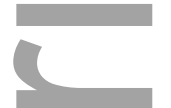

Background - The purpose of this study was to evaluate the frequency and characteristics of surgical protocol violations (SPV) among children undergoing surgery for renal tumors who were enrolled on the Children's Oncology Group (COG) renal tumor biology and classification study AREN03B2.

Methods-AREN03B2 opened in February 2006 and as of March 31, 2013, there were 3664 eligible patients. The surgical review forms for 3536 patients with unilateral disease were centrally reviewed for SPVs. The frequency, type, number of violations, institutional prevalence, and quartiles for SPVs were assessed.

Results-Of the 3536 patients, there were a total of 505 with at least one SPV (564 total SPVs reported), for an overall incidence of $14.28 \%$. The types of SPVs included a lack of lymph node sampling in $365(64.7 \%)$, avoidable spill in 61 (10.8\%), biopsy immediately before nephrectomy in $89(15.8 \%)$, an incorrect abdominal incision in $32(5.7 \%)$, and unnecessary resection of organs in 17 (3.0\%). The SPVs occurred in 163/215 participating institutions (75.8\%). For centers with at least $1 \mathrm{SPV}$, the mean number of SPVs reported was $3.10 \pm 2.39$ (mean \pm standard deviation). The incidence of protocol violation per institution ranged from 0 to $67 \%$. Centers with an average of $\leq 1$ case/year had an incidence of SPVs of $12.2 \pm 3.8 \%$, those with an average of $>1$ to $<4$ cases/year $16.4 \pm 3.6 \%$ and those with an average of $\geq 4$ cases/year $12.6 \pm 5.5 \%(\mathrm{p}>0.05)$. 
Conclusion-SPVs that potentially result in additional exposure to chemotherapy and radiation therapy are not uncommon in children undergoing resection of renal malignancies.

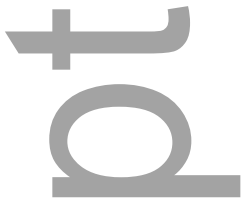

\section{Introduction}

Surgical quality can be defined by structure, process and outcomes measures as well as the appropriateness of the diagnosis and treatment. [1-3] Surgical outcomes can vary by provider and institution. $[1,4,5]$ In adult surgery, factors affecting quality, such as institutional and surgeon volume, and outcomes leading to policies directed at regionalization of care have been explored. [6-9] Recent publications have raised the issue of regionalization in pediatric surgery to ensure optimal care, but data are limited for pediatric surgical conditions. [10-12] The American College of Surgeons Pediatric National Surgical Quality Improvement Program-Pediatric (NSQIP-Peds), and Pediatric Trauma Quality Improvement Program are attempting to address this issue, yet both initiatives are in their infancy. Furthermore, neither of these programs benchmark surgical care for pediatric cancer.

Optimization of care includes implementation of best practice guidelines that are designed to improve outcomes. Clinically meaningful evidence-based guidelines for the surgical management of renal tumors in children have been summarized based on data obtained through the National Wilms Tumor Study Group (NWTSG) and Societe Internationale d'Oncologie Pediatrique (SIOP). These include proper incisions, sampling of lymph nodes, avoidance of intraoperative biopsy and unnecessary resection of other organs.[13-16] Proper surgical management is critical for risk-based therapy. Incorrect or incomplete procedures can expose the patient to excess therapy, with potential short and long term toxicities. Incomplete procedures may also result in under treatment, leading to a higher risk of 
recurrence. Failure to follow evidence-based guidelines for a procedure that affects subsequent therapy can be considered a marker of suboptimal surgical quality.

The NWTSG previously reported that there were opportunities to improve surgical quality for children with renal tumors. This study was limited by small sample size, incomplete operative reports and time delays from surgery to evaluation operative reports. This delay could be longer than a year, during which time a similar mistake could be made and case recollection limited. [13] In 2006 the Children's Oncology Group (COG) opened the AREN03B2 Renal Tumor Biology and Classification study to classify patients with renal tumors to properly define eligibility for a series of therapeutic studies.[17, 18] This process involves real-time central review of pathology slides, radiology studies and operative reports, including surgical assignment of local and overall disease stage as well as documentation of protocol violations. The surgical review allows for assessment of adherence to the protocolspecified guidelines, which provides a measure of institutional surgical quality. The purpose of the current study was to evaluate the characteristics and institutional rate of surgical protocol violations (SPV) from the AREN03B2 study.

\section{Methods}

Enrollment on AREN03B2

All COG participating institutions $(\mathrm{n}=215)$ had active institutional review board approval of the study protocol to enroll a patient. At the time of enrollment, the institution was required to submit key information for central imaging review: operative notes, pathology and biological specimens (for centralized loss of heterozygosity testing at $1 p$ and $16 q$ ), a chest computed tomography scan, and abdomen/pelvis contrast-enhanced computed tomography scan or magnetic resonance imaging. The institution also had to submit institutional radiology, 
pathology, and staging documents. Central radiological review occurred first and assessed the presence of lung metastasis and bilateral renal lesions. Pathology specimens were reviewed for histological diagnosis and assignment of a pathological local stage from I-III. Operative notes were reviewed for rationale for surgical approach, tumor extent, presence or absence of documented rupture or other factors that impact local disease stage, and protocol compliance. The central review surgeons combined the review of the operative reports with the radiological and pathological review to assign a local and overall disease stage and document any SPV. A pediatric oncologist then collated the data from the discipline reviews to determine initial risk classification and therapeutic protocol eligibility.

\section{Surgery for Renal Tumors}

The "gold standard" surgical protocol for unilateral Wilms tumor is a radical nephroureterectomy with lymph node sampling. This procedure has been well established based upon four decades of controlled trials from the NWTSG, COG and SIOP .[14, 15, 17 21] A generous transabdominal, transperitoneal or thoracoabdominal incision is used for adequate exposure. Retroperitoneal incisions have resulted in inadequate staging and visualization especially of the contralateral side.[13-16, 21] Complete exploration of the abdomen and lymph node sampling should be performed. The ureter should be divided as distally as possible. Wilms tumors are frequently adherent to adjacent organs but frank invasion by the tumor is rare. Radical en bloc resection, such as a partial hepatectomy is not warranted.[22] Extensive resection is also not warranted, including multiple organs, e.g. spleen, pancreas, and colon, as these types of procedures are associated with an increased frequency of complications and do not improve survival.[14-16] Removal of a small section of the diaphragm is allowed. 
SPV were defined as any variation from the above protocol and included: lack of any lymph node sampling, incorrect abdominal incision, avoidable spill, unnecessary resection of organs and biopsy immediately before nephrectomy.[13] . An incorrect incision was considered a paramedian or a retroperitoneal incision, however laparoscopy while not encouraged was not considered a SPV. Avoidable spill was difficult to assess as it required the surgical central reviewer to retrospectively assess a surgeon's judgment and technical skills. An avoidable spill was only deemed to have occurred when there was an unwarranted renal biopsy prior to resections or if during the operation the surgeon excised organs inappropriately and the tumor ruptured. If there was a concern about the type of tumor (ie neuroblastoma, lymphoma and the biopsy was for diagnostic purposed these were not considered a protocol violation. Unexpected ruptures during the operation were not considered protocol violations as some tumors can be very friable and it is recognized that tumor rupture may occur despite following all the steps in a protocol. From 2006 to 2008 , when a SPV was identified an education letter was sent to the operating surgeon and the COG institutional Principal Investigator . This program was halted in 2008 due to a change in group policy.

The target patient sample included all eligible patients enrolled on AREN03B2 as of March 31, 2013. Patients with unilateral surgical review forms, which contain the information of interest relating to SPV, were included in the analytic cohort. Central review was performed only on the initial surgery whether it was a primary nephrectomy or biopsy. Those patients who were biopsied and then underwent a delayed nephrectomy, the delayed nephrectomy could not be evaluated for SPV as this data was not collected. A "routine "biopsy and nephrectomy at the time of surgery were not classified as a SPV nor was an SPV recorded if there was concern that a lesion was a neuroblastoma or a lymphoma. 
Frequency tables were used to summarize the types of SPV and the number of violations by institution in and outside the United States (US). The frequency, type, number of violations, institutional prevalence, and quartiles are presented. In addition, the Wilcoxon rank-sum test was used to compare the occurrence of SPV by case volume (average of $\leq 1$ vs. $>1$ to $<4$ vs. $\geq 4$ cases/year), which takes the ordering of the categories into account. A p-value $<0.05$ was considered statistically significant. For the purpose of this report institutions which averaged one or less Wilms tumor resections a year were considered low volume, $>1$ to $<4$ mid volume and $\geq 4$ as high volume. SPV were also analyzed by age of the patient, tumor size, tumor side (right or left) and tumor stage. We could not asses SPV by vascular extent as this data was not collected. Furthermore most tumors that extended into the IV were biopsied and given preop chemotherapy.

\section{Results}

Between February 2006 and March 31, 2013, there were 3,664 patients who began enrollment on AREN03B2, of which 3536 with unilateral tumors had properly submitted all documents for central review. There were 564 SPV determined from central review among 505 patients, for an overall prevalence of $14.28 \%$. The types of SPV are described in Table 1. SPV occurred in 163/215 institutions (75.8\%). Figure 1 shows the frequency distribution of the number of SPV by institution. For centers with at least 1 SPV reported, the mean number of SPV identified was $3.10 \pm 2.39$ (mean \pm standard deviation). Figure 2 shows the breakdown of the number of SPV by quartiles. The prevalence of SPV per institution ranged from 0 to $67 \%$ of the patients undergoing surgery. The prevalence of SPV did not differ between high volume and low volume centers. Centers with an average of $\leq 1$ case/year(76 
centers) had an SPV prevalence of $12.2 \pm 3.8 \%$, those with an average of $>1$ to $<4$ cases/year (86 centers) had an SPV prevalence of $16.4 \pm 3.6 \%$ and those with an average of $\geq 4$ cases/year (55 centers) had an SPV prevalence of $12.6 \pm 5.5 \%$ (p-value $<0.05)$. Figure 2 shows SPV by institution as a percentage of the total number of renal tumor cases performed during the study time period. Sixty one institutions had a SPV in $20 \%$ or more of their renal tumor cases. The 52 centers with no protocols violations were equally comprised of centers with $\leq 1,>1$ to $<4, \geq 4$ cases/year. There was no difference between the size of the centers A significant difference was found between the laterality groups using the chi-square test (pvalue $=0.0045$ ), with right-sided tumors having significantly more violations. A significant difference was found between the age groups using the chi-square test (p-value $<0.0001$ ) and the Cochran-Armitage test for trend also showed an increasing chance of violations with increasing age (one-sided $p$-value $=0.0006)$. A significant difference was found between the disease stage groups using the chi-square test (p-value=0.0002), with stage 3 tumors having significantly more violation

\section{Discussion}

Patients, families, insurance companies and hospitals are invested in improving the quality and safety of health care, especially surgical procedures. [1-3] Compared to the adult literature few studies in children have examined quality for surgery in general and almost none in cancer.[11,19] McAteer et al showed that between 1987 and 2009 the percentage of pyloric stenosis and appendicitis operations (in children less than five) occurring in pediatric hospitals rather than general hospitals has increased, with a significant reduction of complications.[10] One barrier to performing surgical quality studies is that the number of pediatric surgical cases performed per year at any single indication is dwarfed by the number of adult cases. Index pediatric surgical cases are rare, for example the average pediatric 
surgeon performs less than one correction of biliary atresia each year. When volumeoutcome relationships have been examined, the data have been mixed.[11, 23, 24] Process measures (such as wound infection) are similarly hard to evaluate because an event such as wound infection from hernia surgery is inherently rare. A similar problem exists with studying outcomes such as mortality, which is fortunately uncommon.

In the current study we evaluated adherence to protocol-directed surgical resection guidelines as a surrogate for surgical quality. All of the protocol guidelines were evidence-based and instituted to minimize morbidity and mortality. An incorrect incision limits exposure, increases the risk of inaccurately determining the burden of disease and increases the risk of tumor spill. Lack of regional lymph node sampling interferes with tumor staging and may have consequences for outcome, as lymph node status is a major long term predictor of relapse-free and overall survival.[25] Unnecessary resection of adjacent organs is associated with a higher complication rate.[15, 21] A biopsy before nephrectomy (for COG studies) constitutes an intraoperative spill, which increases the need for addition chemotherapy and radiation therapy.[16] These two therapies increase the risk of second malignancies, cardiac disease and premature labor.[26, 27] Previously we defined specific risk characteristics of intra-abdominal spill and demonstrated that spill alone is a frequent cause for the tumor to be upstaged to Stage III which mandates the addition of chemotherapy and radiation.[28]

The current study showed significant surgical variability from protocol guidelines for the resection of childhood renal tumors. We found an almost $15 \%$ prevalence of SPV with most institutions (76\%) having at least one SPV. The most common SPV was failure to sample lymph nodes, accounting for nearly $65 \%$ of SPV. This is an important violation because data from the NTWSG indicated that failure to sample lymph nodes was associated with increased risk of recurrence compared to patients who had lymph nodes sampling, either with 
histologically negative or positive lymph nodes.[16] The second most common SPV was biopsy before nephrectomy, accounting for nearly $16 \%$ of SPV. Intraoperative biopsy before nephrectomy has been considered to be a criterion for stage III disease on NWTSG, SIOP and COG studies based on the presumption that open biopsy causes tumor spillage, which in turn has been associated with increased risk of recurrence.[16] The staging implications of percutaneous needle biopsy are less uniform; tumors undergoing needle biopsy are not necessarily considered to be stage III in the NWTS and SIOP staging systems, but are considered to be stage III in the current COG staging system.

In contrast to other studies, we did not find a lower rate of SPV in institutions with higher surgical volume.[29, 30] However, the absence of a relationship may be misleading. There are only 600-700 renal tumors per year registered on the COG AREN03B2, which makes the number of renal tumor procedures small compared to the number of procedures for adult cancer and other pediatric conditions. It is possible that a relationship between institutional volume and quality could not be established based on the relatively small case volume, even at the larger institutions. Moreover, larger institutions tend to have more cases but also more surgeons and very few institutions have dedicated pediatric cancer surgeons. Therefore, it is possible that a higher institutional case volume is counterbalanced by more surgeons performing cancer surgery, so that a given surgeon may only perform pediatric renal tumor surgery once every couple of years. Regionalization of care for operations/trauma has become more common in the adult world. This does occur for cardiac surgery in children but has only recently gained traction general pediatric surgery.[31] The American College of Surgeons has now developed standards and verification program for the, "optimal resources for children's surgical care." If the 52 centers that did not have a protocol violation did all the cases in the study period it would only average 10 per year.

This article is protected by copyright. All rights reserved. 
Our study has several limitations. First, SPV were defined as deviations from protocol guidelines, which were based on findings from previous clinical trials. Some of the guidelines were supported by stronger levels of evidence than others, and it is possible that surgical guidelines will evolve as more data emerges. It is also possible that extenuating circumstances in individual patients may have justified deviations from the guidelines. Second, treatment, outcome and toxicity data for patients with SPV were not assessed in this study and will be the subject of a future report. Third, our assessment of SPV was based on information provided in the operative notes and, therefore, may have been limited if details about the procedure were omitted. For instance, avoidable intraoperative spill was hard to determine and surgeons were given the benefit of the doubt if there was a question. The study may have underestimated the true prevalence of SPV.

The relatively high rate of SPV indicates that there is opportunity for improvement in surgical quality for patients undergoing surgery for pediatric renal tumors. Strategies used to improve surgical quality have shown mixed results. Surgical quality has been shown to improve when valid evidence-based guidelines are made available, but this appears to take a long time to implement. $[32,33]$ Targeted feedback, especially for cancer treatment, has shown the greatest promise. A breast cancer study designed to improve the use of appropriate adjuvant therapy used a registry to identify patients who would benefit adjuvant therapy. The intervention was direct feedback to the surgeon informing them of whether their patient was offered appropriate adjuvant therapy. The intervention decreased the number of patients who were not receiving appropriate adjuvant therapy (23\% before vs. $14 \%$ after the intervention; difference $-9 \%, 95 \% \mathrm{CI}-12 \%$ to $-6 \%, \mathrm{p}<0.001)$. [34] This example suggests the value of correctly targeted feedback within the decision pathway. 
The COG Renal Tumor Committee has taken several approaches to improve surgical quality. Several years ago a "one minute update for surgeons" was made available on the COG website for each solid organ tumor. Over the past several years, didactic renal tumor sessions have been given at the major pediatric surgery and urological meeting as well as a number of "e-blasts" on the major society websites. Going forward, user-friendly surgical guidelines and checklists will be disseminated to COG institutions to provide to surgeons before renal tumor surgery. Such checklists are used routinely before and after operative procedures in the United States and elsewhere to standardize procedures according to best clinical practice. Another potential intervention is to revisit the practice of providing institutional feedback when a SPV is identified. This practice was in effect from 2006-2008 but was stopped after an institution expressed concern about ramifications of the feedback, including medicolegal concerns. Targeted institutional feedback from adult programs such as NSQIP have driven improvements in surgical and trauma care and could be helpful in optimizing care for pediatric cancer surgery.[7, 35, 36] It may be useful to create benchmark data such as created by NSQIP so that positive outliers can be identified. Such institutions may be studied further to determine "best practices" for others to emulate. On a broader scale, institutions may consider limiting the number of surgeons who perform surgery for pediatric renal tumors or designate an institutional surgical expert to review the protocol with the operating surgeon and oncology team. As regionalization and optimization of care are being driven by insurance companies, such quality control measures are likely to be required.

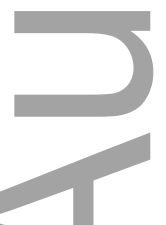

\section{REFERENCES}

1. Birkmeyer JD, Dimick JB, Birkmeyer NJ. Measuring the quality of surgical care: structure, process, or outcomes? J Am Coll Surg. 2004;198:626-632.

2. Cooperberg MR, Birkmeyer JD, Litwin MS. Defining high quality health care. Urol Oncol. 2009;27:411-416. 
3. Clavien PA. Targeting quality in surgery. Ann Surg. 2013;258:659-668.

4. Khuri SF, Daley J, Henderson W Hur K, Gibbs JO, Barbour G, Demakis J, , Stremple JF, Grover F, McDonald G, Passaro E Jr, Fabri PJ, Spencer J,Hammermeister K, Aust JB. Risk adjustment of the postoperative mortality rate for the comparative assessment of the quality of surgical care: results of the National Veterans Affairs Surgical Risk Study. J Am Coll Surg. 1997; 185:315-327.

5. O'Connor GT, Plume SK, Olmstead EM Coffin LH, Morton JR, Maloney CT, Nowicki ER, Tryzelaar JF, Hernandez F, Adrian 1 Casey KJ, Soule DN; Marrin CA,Nugent WC, Charlesworth DC, Clough R, Katz S, Leavitt BJ , Wennberg JE. A regional prospective study of in-hospital mortality associated with coronary artery bypass grafting. The Northern New England Cardiovascular Disease Study Group. JAMA. 1991;266:803-809.

6. Birkmeyer JD, Dimick JB, Staiger DO. Operative mortality and procedure volume as predictors of subsequent hospital performance. Ann Surg. 2006;243:411-417.

7. Birkmeyer JD, Shahian DM, Dimick JB Finlayson SR, Flum DR, Ko CY, Hall BL. Blueprint for a new American College of Surgeons: National Surgical Quality Improvement Program. J Am Coll Surg. 2008;207:777-782.

8.Dimick JB, Staiger DO, Osborne NH, Nicholas LH, Birkmeyer JD. Composite measures for rating hospital quality with major surgery. Health Serv Res. 2012;47:1861-1879.

9. Sonnenday CJ, Birkmeyer JD. A tale of two provinces: regionalization of pancreatic surgery in Ontario and Quebec. Ann Surg Oncol. 2010;17:2535-2536.

10. McAteer JP, Lariviere CA, Oldham KT, Goldin AB. Shifts towards pediatric specialists in the treatment of appendicitis and pyloric stenosis: Trends and outcomes. J Pediatr Surg. 2014;49:123-128.

11. McAteer JP, Lariviere CA, Drugas GT, Abdullah F, Oldham KT, Goldin AB. Influence of surgeon experience, hospital volume, and specialty designation on outcomes in pediatric surgery: a systematic review. JAMA Pediatr. 2013;167:468-475.

12. Vinocur JM, Menk JS, Connett J, Moller JH, Kochilas LK. Surgical volume and center effects on early mortality after pediatric cardiac surgery: 25-year North American experience from a multi-institutional registry. Pediatr Cardiol. 2013;34:1226-1236.

13. Ehrlich PF, Ritchey ML, Hamilton TE, Haase GM, Ou S, Breslow N, Grundy P, Green D, Norkool P, Becker J, Shamberger RC. Quality assessment for Wilms' tumor: a report from the National Wilms' Tumor Study-5. J Pediatr Surg. 2005;40:208-212.

14. Ritchey ML, Kelalis P, Breslow N, Etzioni R, Evans I, Haase GM, D'Angio GJ. Surgical complications after nephrectomy for Wilms tumor. Surg Gynecol Obstet. 1992;175:514. 
15. Ritchey ML, Shamberger RC, Haase G, Horwitz J, Bergemann TL. Surgical complications after primary nephrectomy for Wilms' tumor: report from the National Wilms' Tumor Study Group. J Am Col Surg. 2001;192:63-68.

16. Shamberger RC, Guthrie KA, Ritchey ML Haase GM, Takashima J, Beckwith JB, D'Angio GJ, Green DM, Breslow NE.. Surgery related factors and local reccurance of Wilms tumor in the national Wilms tumor study 4. Ann Surg. 1999;229:292-297.

17. Mullen E, Geller JI, Ehrlich PF, Dome JS, Perlman EJ, Khanna G . Real Time Central Review and Risk Stratification is feasible improves study quality and risk based therapy. A report from the Children's Oncology Group (COG) Renal Tumor Biology and Risk Stratifications Protocol ARENO3B2. J Clin Oncol. 32[15]. 2014.

18. Mullen E, Geller JI, Ehrlich PF, Dome JS, Perlman EJ Khanna G. First 4000 Patients on Children's Oncology Group (COG) Renal Tumor (RT) Risk Stratification and Biology Protocol AREN03B2. Pediatr Blood and Cancer 61[S2], S105-S440. 2014.

19. Fuchs J, Kienecker K, Furtwängler R.,Warmann SW, Burgher D, Thuroff JW, Hager J, Graf N Surgical aspects in the treatment of patients with unilateral wilms tumor: a report from the SIOP 93-01/German Society of Pediatric Oncology and Hematology. Ann Surg. 2009;249:666-671.

20. Grundy PE, Dome JS, Ehrlich PF, Perlman EP Renal tumors classification, biology and banking studies.

https://members.childrensoncologygroup.org/Prot/AREN03B2/AREN03B2DOC.pdf , 18-33. 2012.

21. Ritchey ML, Lally KP, Haase GM, Shochat SJ, Kelalis PP. Superior mesenteric artery injury during nephrectomy for Wilms' tumor. J Pediatr Surg. 1992;27:612-615.

22. Ehrlich PF, Ferrer FA, Ritchey ML, Anderson JR, Green DM, Grundy PE, Dome JS, Kalapurakal JA, Perlman EJ, Shamberger RC.. Hepatic Metastasis At Diagnosis In Patients With Wilms Tumor Is Not An Independent Adverse Prognostic Factor For Stage V Wilms Tumor. A Report From The Childrens Oncology Group/National Wilms Tumor Study Group. Ann Surg. 2009;250:642-648.

23. Davis JS, Ryan ML, Perez EA, Neville HL, Bronson SN, Sola JE. ECMO hospital volume and survival in congenital diaphragmatic hernia repair. J Surg Res. 2012;178:791796.

24. Liu M, Druschel CM, Hannan EL. Risk-Adjusted Prolonged Length of Stay as an Alternative Outcome Measure for Pediatric Congenital Cardiac Surgery. Ann Thorac Surg. 2014.

25. Ehrlich PF, Anderson JR, Ritchey ML, Dome JS, Green DM, Grundy PE, Perlman EJ, Kalapurakal JA, Breslow NE, Shamberger RC . Clinico-pathologic Findings Predictive Of 
Relapse In Children With Stage III Favorable Histology Wilms Tumor: The Importance Of Lymph Nodes . J Clin Oncol 2013 Mar 20;31(9):1196-201. 2010;31:1196-1201.

26. Green DM, Grigoriev YA, Nan B,Takashima JR, Norkool PA, D'Angio GJ, Breslow NE. Congestive heart failure after treatment for Wilms' tumor: a report from the National Wilms' Tumor Study group. J Clin Oncol. 2001;19:1926-1934.

27. Green DM, Lange JM, Peabody EM. Pregnancy Outcome After Treatment for Wilms Tumor: A Report From the National Wilms Tumor Long-Term Follow-Up Study. J Clin Oncol. 2010;28:2824-30.

28. Gow K, Barnhart DC, Hamilton TE, Kandel JJ, Chen MK, Ferrer FA, Price MR, Mullen EA, Geller JI, Gratias EJ, Rosen N, Khanna G, Naranjo A, Ritchey ML,Grundy PE, Dome JS, Ehrlich PF.. Primary Nephrectomy and Intraoperative Tumor Spill: Report from the Children's Oncology Group (COG) Renal Tumors Committee. J Pediatr Surg. 2013;48:34 38.

29. Reames BN, Ghaferi AA, Birkmeyer JD, Dimick JB. Hospital volume and operative mortality in the modern era. Ann Surg. 2014;260:244-251.

30. Gonzalez AA, Dimick JB, Birkmeyer JD, Ghaferi AA. Understanding the volumeoutcome effect in cardiovascular surgery: the role of failure to rescue. JAMA Surg. 2014;149:119-123.

31. Arca MJ, Goldin AB, Oldham KT. Optimization of care for the pediatric surgical patient: Why now? Semin Pediatr Surg 2015:24:311-314.

32. Smith GL, Xu Y, Shih YC, Giordano SH, Smith BD, Hunt KK, Strom EA, Perkins GH, Hortobagyi GN, Buchholz TA. Breast-conserving surgery in older patients with invasive breast cancer: current patterns of treatment across the United States.. J Am Col Surg. 2009;209:425-433.

33. Birkmeyer JD, Reames BN, McCulloch P, Carr AJ, Campbell WB, Wennberg JE. Understanding of regional variation in the use of surgery. Lancet. 2013;382:1121-1129.

34. Bickell NA, Shastri K, Fei K Oluwole S, Godfrey H, Hiotis K, Srinivasan A, Guth AA.A tracking and feedback registry to reduce racial disparities in breast cancer care. J Natl Cancer Inst. 2008;100:1717-1723.

35. Newgard CD, Fildes JJ, Wu L Hemmila MR, Burd RS, Neal M, Mann NC, Shafi S, Clark DE, Goble S, Nathens AB. Methodology and analytic rationale for the American College of Surgeons Trauma Quality Improvement Program. J Am Coll Surg. 2013;216:147157.

36. Shafi S, Nathens AB, Cryer HG, Hemmila MR, Pasquale MD, Clark DE, Neal M, Goble,S.; Meredith JW Fildes JJ The Trauma Quality Improvement Program of the American College of Surgeons Committee on Trauma. J Am Coll Surg. 2009;209:521-530. 
Table I. Distribution of Types of Surgical Protocol Violations (SPV) on AREN03B2

\begin{tabular}{|l|c|}
\hline Type of Protocol Violation & $\begin{array}{c}\text { Frequency (\% of } \\
\text { SPV) }\end{array}$ \\
\hline Avoidable Spill & $61(10.8)$ \\
\hline Biopsy Before Nephrectomy & $89(15.8)$ \\
\hline Incorrect Abdominal Incision & $32(5.7)$ \\
\hline No Lymph Node Sampling & $365(64.7)$ \\
\hline Unnecessary Resection of Organs & $17(3.0)$ \\
\hline
\end{tabular}

Figures 1.Protocol violations. The $x$ axis lists the number of surgical protocol violations and $y$ axis lists the number of institutions

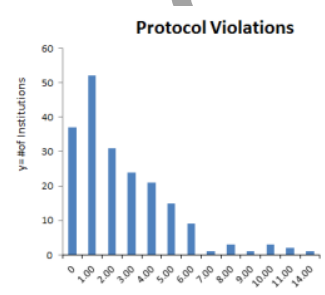

$$
x=\text { of violations }
$$

Figure 2. Surgical Protocol violations by institution as a percentage of the total number of renal tumor cases performed during the study time period

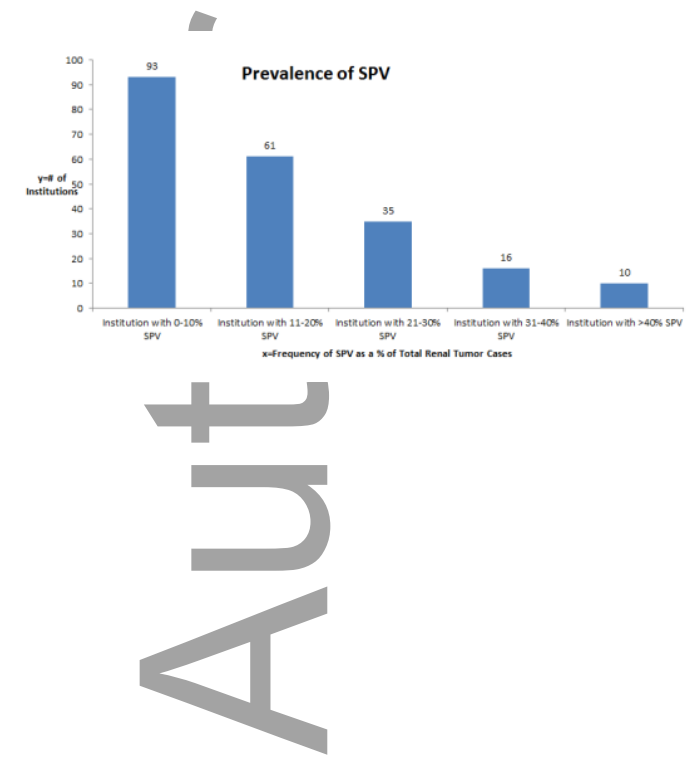

